\title{
Evasão em cursos de educação continuada a distância: um estudo na Escola Nacional de Administração Pública
}

Tarcilena Polisseni Cotta Nascimento e Aniely Kaukab Esper

\section{Introdução}

No cenário do serviço público brasileiro, onde se observa a necessidade de capacitação profissional específica para um quadro de aproximadamente um milhão de servidores públicos federais ativos do Poder Executivo ${ }^{1}$, civis e militares, distribuídos pelo Brasil, e de servidores das esferas estaduais e municipais, a educação continuada a distância constitui importante alternativa de capacitação.

Em novembro de 1995, durante o Governo do Presidente Fernando Henrique Cardoso, o então ministro da Fazenda, Luis Carlos Bresser-Pereira, foi responsável por elaborar e implementar o Plano Diretor da Reforma do Estado como importante estratégia para consolidar a estabilização e a sustentabilização do modelo econômico proposto por aquele governo.

As análises dos especialistas em políticas governamentais da época ressaltavam que a reforma do Estado constituía instrumento fundamental para assegurar o crescimento sustentável da economia, buscando estabelecer modelo 
de desenvolvimento que trouxesse uma perspectiva de melhor futuro para a sociedade brasileira. Um dos esforços principais, nesse sentido, foi o fortalecimento do Estado para uma ação reguladora mais eficaz, tanto na esfera econômica quanto nos serviços prestados e nas políticas sociais a implementar.

O Plano Diretor da Reforma do Estado teve como foco a criação de condições para a reconstrução da administração pública em bases modernas e racionais, em oposição a uma administração formal e de princípios burocráticos. Foram concentrados esforços no sentido de implementar uma administração pública gerencial, norteada por modernos conceitos de administração e eficiência, com controles de resultados e descentralizada, visando, principalmente, à melhoria dos serviços oferecidos ao cidadão, que "se torna cliente privilegiado dos serviços prestados pelo Estado".

Para avançar em direção a formas mais contemporâneas de gestão pública, foi mister compartilhar essa visão com os servidores públicos e levá-los a ter uma percepção renovada de seu papel, pois é nas ações desse segmento que a sociedade percebe as mudanças. Intencionou-se fortemente valorizar o servidor, oferecendo-lhe motivação profissional e abrindo espaços para o exercício da criatividade.

Ao Núcleo Estratégico do Plano Diretor coube, como um de seus objetivos, modernizar a administração democrática, por meio da profissionalização do serviço público, definindo políticas de carreiras, de concursos públicos anuais, de administração salarial e de programas de educação continuada permanente. Com relação ao último aspecto, foram implementadas ações de gestão de recursos humanos para o aperfeiçoamento de capacidades gerenciais e técnicas do setor público, objetivando construir um processo permanente de atualização dos quadros do Estado.

O Plano Diretor da Reforma do Estado destacou como fundamental o papel a ser desempenhado pelas escolas de governo na oferta de programas de treinamento e desenvolvimento de recursos humanos, diretamente voltados aos objetivos da reforma. Essas ações visavam à valorização do servidor público que apresentasse desempenho de qualidade, sendo reconhecido pelo cidadão e contribuindo para consolidação de uma nova imagem do serviço público perante a sociedade.

No esforço de expandir as oportunidades de capacitação para os servidores, em especial para os lotados fora dos grandes centros urbanos, algumas escolas de governo iniciaram atividades de aprendizagem também na modalidade a distância, iniciativa de vanguarda para a época.

Atualmente, apesar dos avanços nesse campo, com destaque especial para as ações de educação a distância empreendidas pela Escola Nacional de Administração Pública (ENAP), verifica-se ainda um percentual de participantes que não concluem as ações de capacitação iniciadas e que formam grupamento de servidores evadidos de cursos a distância. Daí a importância de se investigar o fenômeno da evasão nesse contexto específico para minimizá-lo.

Em razão disso, é propósito deste artigo identificar os fatores que mais contribuem para a evasão de participantes nos cursos de educação continuada a distância em uma organização governamental responsável pela capacitação dos servidores da administração pública federal, a ENAP. 
Objetiva-se identificar quais os elementos, entre as características dos cursos, as condições de trabalho, as questões tecnológicas e os aspectos pessoais, mais motivam as evasões. O artigo também apresenta o perfil dos servidores evadidos nos cursos a distância da ENAP e os principais fatores que os levaram a desistir.

\section{Educação a distância}

Entende-se por educação a distância o processo de ensino-aprendizagem no qual docente e discentes estão em locais e tempos distintos. Assim,

educação a distância é o aprendizado planejado que ocorre normalmente em um lugar diferente do local do ensino, exigindo técnicas especiais de criação do curso e de instrução, comunicação por meio de várias tecnologias e disposições organizacionais e administrativas especiais (Moore; Kearsley, 2007, p. 2).

Litwin (2001 apud WaLter, 2006) afirma que essa modalidade não tem a distância como sua principal característica, pois a virtualidade permite encontros que cada vez mais favorecem a educação. $\mathrm{O}$ fator que realmente diferencia a educação a distância da modalidade presencial é a mediatização das relações entre docentes e discentes, ou entre o aprendiz e a instituição provedora.

\section{A evasão em cursos a distância}

\section{O que é evasão}

O vocábulo 'evasão’ tem origem latina, evasione, que significa fuga, saída, subterfúgio.

De acordo com Maia, Meirelles e Pela (2004), evasão refere-se à situação de estudantes que não completam cursos ou programas de estudo, incluindo os que se matriculam e desistem antes mesmo de iniciar o curso. Para os autores, o êxito em concluir um curso pode ser influenciado pelos seguintes fatores:

uma definição clara do programa, a utilização correta do material didático, o uso correto de meios apropriados que facilitem a interatividade entre

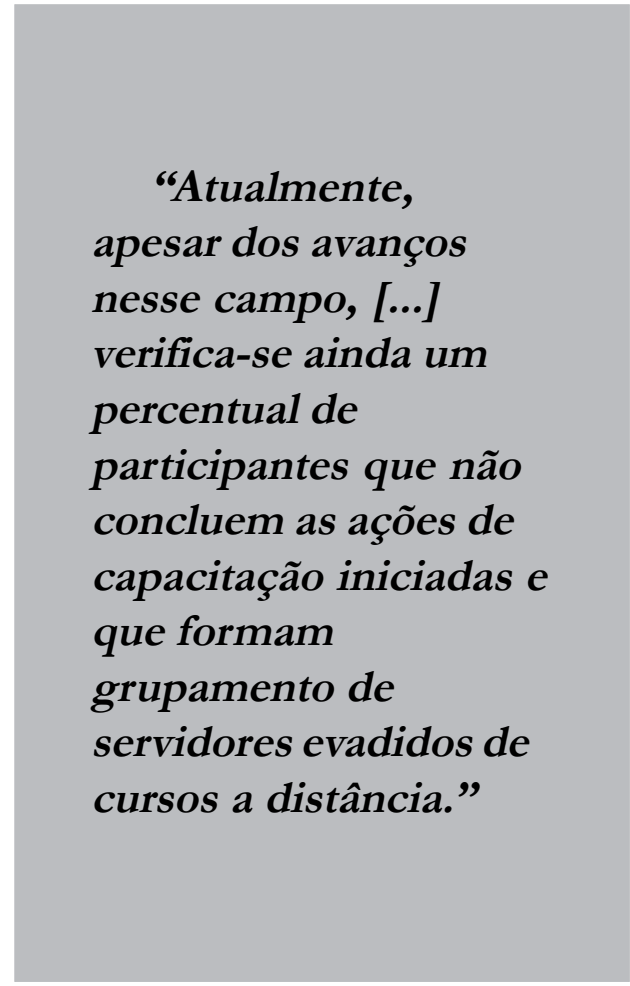

professores e alunos e entre os alunos e a capacitação dos professores. (MAIA; Meirelles e Pela, 2004)

Além desses aspectos, os autores afirmam que o fenômeno da evasão pode ser influenciado por questões individuais e regionais e pela avaliação do curso, podendo ser minimizado com ações preventivas que contemplem esses pontos. 
Para Favero (2006), evasão é a desistência do aluno em completar o curso, incluindo aqueles que, após terem se matriculado, não se manifestaram para os colegas e mediadores do curso, em qualquer momento.

Tresman (2002 apud WALTER, 2006) afirma que estudantes que abandonaram o curso em situações distintas não podem ser tratados sob uma mesma ótica em termos de evasão. Precisam ser observadas as diferentes realidades dos estudantes que não completaram o curso: os que se matricularam, mas não começaram o curso; os que formalmente abandonaram o curso, após seu início; os que se evadiram por não alcançarem os critérios mínimos; e os que mudaram para outra instituição ou outro curso.

Segundo Abbad, Carvalho e Zerbini (2006), o aluno evadido é aquele que desiste definitivamente do curso em qualquer etapa.

Para efeito deste trabalho, decidiu-se considerar como evadidos os participantes que têm, pelo menos, um registro de acesso à sala de aula virtual, porém não concluíram o curso. Os participantes que não chegaram a acessar a sala de aula virtual, foram apartados da análise devendo ser classificados em outra categoria que não nos propusemos a investigar. Também foram excluídos da pesquisa os participantes que trancaram suas matrículas e não mais retornaram ao ambiente virtual de aprendizagem.

Em suma, evasão foi aqui considerada como a desistência do participante em concluir o curso, após o primeiro acesso ao ambiente virtual de aprendizagem, em um momento qualquer.

\section{Estudos e pesquisas em evasão}

Em revisão da literatura sobre o construto 'evasão', são encontradas descrições de fatores como potenciais indutores desse fenômeno. Segundo Coelho (2002), as principais suposições sobre a evasão nos cursos a distância, via internet, são quatro: a falta da tradicional relação face a face entre aluno e professor; o insuficiente domínio técnico do uso do computador por parte do aluno; a dificuldade do aluno em expor ideias em uma comunicação escrita a distância, inviabilizando a interatividade; e a falta de agrupamento de pessoas em uma instituição física.

De acordo com Favero (2006), diversos fatores contribuem para a evasão. Considerando que muitos dos participantes de cursos a distância são adultos trabalhadores entre 25 e 40 anos, uma das causas de evasão é o cansaço no final do dia de trabalho. Existe também o desinteresse pela continuidade dos estudos.

De acordo com o Anuário Brasileiro Estatístico de Educação Aberta e a Distância - Abraead (2006), os motivos frequentemente apontados para a evasão em cursos a distância, em qualquer mídia, são a ausência de tempo e de condições financeiras adequadas por parte do aluno. O documento relata que instituições com maior proporção de alunos por professor/ tutor têm maior evasão.

Conforme o Anuário, a mídia mais utilizada pelas instituições nos cursos a distância no país é o material impresso (86\%) e, em segundo lugar, encontra-se a mídia web ou o e-learning (56\%). Há estudo exploratório indicando que outros fatores são apresentados como de maior influência na evasão, tais como, o estranhamento ao método utilizado, a avaliação de que o curso exige maior dedicação que a inicialmente esperada pelo participante e o entendimento de que o material de estudo e os recursos oferecidos foram escassos. 


\section{Aspectos metodológicos da pesquisa}

De acordo com Gil (1999), pesquisa é o processo formal e sistemático de desenvolvimento de método científico, com o objetivo de responder a problemas mediante o emprego de procedimentos científicos.

\section{Tipo de pesquisa}

O presente trabalho é embasado em metodologia quantitativa, por meio de pesquisa descritiva de campo junto aos participantes buscando identificar quais fatores contribuem de modo mais significativo para a evasão de servidores nos cursos a distância da ENAP, valendo-se do uso de questionário eletrônico.

\section{Organização pesquisada}

A pesquisa foi realizada na Escola Nacional de Administração Pública (ENAP) que tem como missão "desenvolver competências de servidores públicos para aumentar a capacidade de governo na gestão das políticas públicas".

À ENAP cabe o papel estratégico de formação de quadros dirigentes e de coordenação do Sistema de Escolas de Governo da União.

Em junho de 2004, foi criada a Coordenação-Geral de Educação a Distância (CGEAD) para adoção dessa modalidade de ensino-aprendizagem como linha de trabalho estratégica para a capacitação dos servidores públicos brasileiros atendidos pela ENAP. Em outubro de 2004, iniciaram-se as atividades de sua Escola Virtual.

Desde a criação da Escola Virtual ENAP até dezembro de 2008, cerca de 50 mil servidores públicos concluíram cursos a distância. Mais de 19 mil capacitações foram realizadas somente nesse último ano.

\section{Cursos pesquisados}

Constituíram o objeto da presente pesquisa somente cursos desenvolvidos ou adaptados pela Coordenação-Geral de Educação a Distância da ENAP no período compreendido entre outubro de 2004 e dezembro de 2007. São eles: Análise e Melhoria de Processos; Orçamento Público: elaboração e execução; Atendimento ao Cidadão; E-mag Modelo de Acessibilidade em Governo Eletrônico; Ética e Serviço Público; Gestão Estratégica de Pessoas e Planos de Carreira; Legislação Aplicada à Gestão de Pessoas - Lei no 8.112/90 e Legislação Complementar; Legislação Aplicada à Logística de Suprimentos; e Rumo à Aprendizagem Virtual.

Os cursos "Análise e Melhoria de Processos" e "Orçamento Público: elaboração e execução" possuem estudos e exercícios em sala de aula virtual, com utilização de correio eletrônico, sala de batepapo (chats), fóruns pontuados, glossários, biblioteca e contam com a assistência de tutores para esclarecimento de dúvidas.

Os demais cursos não possuem tutoria. Em linhas gerais, apresentam as mesmas características. Os conteúdos são disponibilizados em ambiente virtual e contam com recursos como salas de batepapo (chats), glossário e material na biblioteca.

Não é permitido ao participante navegar livremente entre os módulos, pois os conhecimentos a serem apreendidos seguem sequência gradativa de complexidade sendo, portanto, necessário seguir a ordem em que os módulos são apresentados e realizar os respectivos exercícios de aprendizagem. Foge à essa regra o curso "Rumo à Aprendizagem Virtual", no qual o participante pode ir e vir, livremente, entre os módulos. 
Para ser considerado concluinte, é obrigatório que o participante responda as atividades com, no mínimo, $60 \%$ de acerto e preencha a avaliação de satisfação com o curso.

\section{Participantes da pesquisa}

Foram convidados a participar da pesquisa 1.923 servidores públicos que não concluíram um ou mais cursos de educação continuada a distância desenvolvidos ou adaptados pela ENAP e oferecidos gratuitamente aos servidores públicos de todo o território nacional.

Desses, 648 responderam ao questionário disponibilizado por meio eletrônico no período de 13/06/2007 a 26/09/2007, conforme Tabela 1.

Comparando-se a participação em cursos com e sem tutoria, pode-se verificar algumas diferenças no perfil de evadidos (Tabela 2).
Instrumento da pesquisa, procedimentos de coleta de dados e de análise de dados

Durante o ano de 2005, a Coordenação-Geral de Educação a Distância desenvolveu seu primeiro instrumento de pesquisa sobre causas de evasão contendo 13 itens e abordando três áreas de possíveis dificuldades: pessoais, profissionais e tecnológicas.

Em dezembro de 2006, foi feita a revisão do instrumento e realizada a validação semântica com dois grupos de indivíduos: servidores da própria ENAP e servidores do Ministério do Trabalho e Emprego e da Previdência Social.

Dessa forma, o novo instrumento, base para este trabalho, foi constituído por 32 itens fechados, distribuídos em quatro seções relacionadas às dificuldades pessoais, profissionais, tecnológicas e às características do curso.

Tabela 1: Participantes evadidos $\mathrm{x}$ Respostas recebidas por curso

\begin{tabular}{|c|c|c|c|}
\hline Cursos & $\begin{array}{c}\mathbf{N}^{0} \text { de } \\
\text { matriculados }\end{array}$ & $\begin{array}{c}\mathbf{N}^{\circ} \text { de } \\
\text { Evadidos }\end{array}$ & $\begin{array}{c}N^{0} \text { Respostas } \\
\text { recebidas }\end{array}$ \\
\hline Análise e Melhoria de Processos & 442 & 135 & 49 \\
\hline Atendimento ao Cidadão & 1.473 & 135 & 60 \\
\hline E-mag & 453 & 57 & 12 \\
\hline Ética e Serviço Público & 1.176 & 140 & 55 \\
\hline $\begin{array}{l}\text { Gestão Estratégica de Pessoas e Planos } \\
\text { de Carreira }\end{array}$ & 2.018 & 375 & 142 \\
\hline $\begin{array}{l}\text { Legislação Aplicada à Gestão de Pessoas - } \\
\text { Lei no }^{\circ} 8.112 / 90 \text { e Legislação Complementar }\end{array}$ & 1.939 & 347 & 146 \\
\hline $\begin{array}{l}\text { Legislação Aplicada à Logística de } \\
\text { Suprimentos }\end{array}$ & 1.965 & 359 & 54 \\
\hline $\begin{array}{l}\text { Orçamento Público: elaboração e } \\
\text { execução }\end{array}$ & 559 & 106 & 39 \\
\hline Rumo à Aprendizagem Virtual & 1.223 & 269 & 91 \\
\hline Total & 11.248 & 1.923 & 648 \\
\hline
\end{tabular}


Tabela 2: Dados demográficos de evadidos em cursos com e sem tutoria

\begin{tabular}{llcllc}
\hline \multirow{2}{*}{ Dados } & \multicolumn{2}{c}{ Cursos com Tutoria } & \multicolumn{2}{c}{ Cursos sem Tutoria } \\
\cline { 2 - 5 } & Concentração & Percentual & Concentração & Percentual \\
\hline Faixa Etária & De 30 a 39 anos & $39,8 \%$ & De 30 a 39 anos & $34,6 \%$ \\
Gênero & Masculino & $52,3 \%$ & Feminino & $54,8 \%$ \\
\hline Região Geográfica & Centro-Oeste & $39,8 \%$ & Centro-Oeste & $36,3 \%$ \\
\hline Escolaridade & Graduação & $39,8 \%$ & Graduação & $40,7 \%$ \\
\hline Poder & Executivo & $77,3 \%$ & Executivo & $77,3 \%$ \\
\hline Esfera de Governo & Federal & $71,6 \%$ & Federal & $83,0 \%$ \\
\hline
\end{tabular}

Para viabilizar a remessa e a coleta eletrônica de dados, foi desenvolvido pela área técnica da Escola um sistema de avaliação, denominado WebAVAL, no qual foram cadastrados os itens do instrumento de pesquisa e armazenados os dados coletados. O sistema foi elaborado de forma a não permitir a devolução de questionário, pelo participante, com questões em branco. Por esse motivo, todas as respostas recebidas puderam ser consideradas.

Após a coleta de dados, utilizou-se o programa Statistical Packeage for Social Sciences (SPSS) para realização das análises estatísticas descritivas, a partir dos agrupamentos de frequência, percentual, média e desviopadrão.

\section{Resultados}

\section{Perfil dos evadidos}

Os servidores evadidos estão concentrados na faixa etária de 30 a 39 anos $(35,3 \%)$, independentemente do tipo de curso, com ou sem tutoria.

Quanto ao gênero, constatou-se ligeira diferença, sendo que as mulheres $(53,9 \%)$ evadem mais dos cursos a distância e, em especial, dos cursos sem tutoria (54,8\%), enquanto os homens evadem mais dos cursos com tutoria $(52,3 \%)$.
Os evadidos estão, geograficamente, distribuídos por todas as regiões brasileiras, sendo que a maior concentração se dá na Região Centro-Oeste (36,7\%), seguida pela Região Sudeste (29,5\%), independentemente do tipo de curso.

Quanto à escolaridade dos evadidos, identificou-se que $40,6 \%$ possuem graduação completa e 16,2\% pós-graduação. Essa distribuição é a mesma para ambos os tipos de curso.

Verificou-se ainda que $77,3 \%$ dos evadidos são do poder executivo, seja nos cursos com ou sem tutoria e que $81,5 \%$ dos evadidos são da esfera federal, público-alvo prioritário da capacitação da ENAP, seguida pela esfera municipal, com 10,2\%.

\section{Fatores que afetam a evasão nos} cursos a distância da ENAP

Nesta parte, são apresentadas as análises descritivas das respostas relativas ao questionário de evasão. Essas análises são apresentadas separadas pelas seções do questionário, a saber, dificuldades pessoais, características do curso, dificuldades profissionais e dificuldades tecnológicas.

Receberam o questionário de pesquisa 1.923 participantes que não haviam concluído um ou mais cursos a distância oferecidos pela Coordenação-Geral de Educação a Distância da ENAP. O índice 
de retorno dos questionários foi de 33,69\%, o que corresponde a 648 respondentes.

Os respondentes do questionário utilizaram escala Likert de concordância com 11 pontos.

Na Tabela 3, os dados relativos a "Dificuldades Pessoais" são apresentados quanto à soma de respostas nos pontos 8 , 9 e 10 da escala Likert adotada, seu percentual em relação ao total de respondentes, média e desvio-padrão (dp).

Observa-se que os itens com maior média foram: "Fiquei doente durante o período de realização do curso" (média= 3,88; dp=4,459) e "Tive dificuldade em conciliar a execução do curso com meus compromissos familiares" (média $=3,86$; $\mathrm{dp}=4,138)$. Isso significa que, dentre as dificuldades pessoais, doenças e compro- missos familiares foram as que mais motivaram a desistência do curso. Vale ressaltar que o desvio-padrão em ambos os itens mostrou-se alto, o que representa uma heterogeneidade de respostas entre os participantes evadidos.

A Tabela 4 apresenta os dados referentes a "Características do Curso" em relação à soma de respostas nos pontos 8, 9 e 10 da escala, seu percentual em relação ao total de respondentes, média e desvio-padrão.

Analisando a Tabela 4, verifica-se que as médias dos itens referentes às "Características do Curso" foram todas menores que 1,6 e que os desvios-padrão foram relativamente baixos. Isso significa que as características do curso parecem influenciar menos a evasão que outros aspectos analisados na presente pesquisa.

\section{Escala de concordância utilizada de 11 pontos (Likert)}

\begin{tabular}{|c|c|c|c|c|c|c|c|c|c|c|c|}
\hline 0 & 1 & 2 & 3 & 4 & 5 & 6 & 7 & 8 & 9 & 10 & NA \\
\hline $\begin{array}{l}\text { Disc } \\
\text { total }\end{array}$ & & & & & & & & & \multicolumn{2}{|c|}{$\begin{array}{l}\text { Concordo } \\
\text { totalmente }\end{array}$} & $\begin{array}{l}\text { Não se } \\
\text { Aplica }\end{array}$ \\
\hline
\end{tabular}

Tabela 3: Dificuldades pessoais como causas de evasão

\begin{tabular}{|c|c|c|c|c|}
\hline \multirow{2}{*}{ Dificuldades Pessoais } & \multirow{2}{*}{ Média } & \multirow{2}{*}{$\begin{array}{l}\text { Desvio- } \\
\text { padrão }\end{array}$} & \multicolumn{2}{|c|}{ Itens 8,9 e 10} \\
\hline & & & Soma & $\%$ \\
\hline $\begin{array}{l}\text { É pouco motivador participar de um curso a } \\
\text { distância. }\end{array}$ & 1,26 & 2,327 & 17 & $2,26 \%$ \\
\hline $\begin{array}{l}\text { Fiquei doente durante o período de realização } \\
\text { do curso. }\end{array}$ & 3,88 & 4,549 & 143 & $22,07 \%$ \\
\hline $\begin{array}{l}\text { Minha habilidade em digitação atrapalhou } \\
\text { meu desempenho no curso. }\end{array}$ & 0,31 & 1,357 & 5 & $0,77 \%$ \\
\hline $\begin{array}{l}\text { Estudar na tela do computador é difícil para } \\
\text { mim. }\end{array}$ & 1,50 & 2,672 & 26 & $4,01 \%$ \\
\hline $\begin{array}{l}\text { Não tive um computador disponível durante o } \\
\text { período do curso. }\end{array}$ & 3,40 & 4,229 & 125 & $19,29 \%$ \\
\hline $\begin{array}{l}\text { Meu conhecimento técnico em informática foi } \\
\text { insuficiente para realizar o curso. }\end{array}$ & 0,33 & 1,419 & 8 & $1,23 \%$ \\
\hline Tenho dificuldades em estudar sozinho. & 0,81 & 2,070 & 13 & $2,01 \%$ \\
\hline $\begin{array}{l}\text { Tive dificuldade em conciliar a execução do } \\
\text { curso com meus compromissos familiares. }\end{array}$ & 3,86 & 4,138 & 134 & $20,68 \%$ \\
\hline
\end{tabular}




\section{Tabela 4: Características do curso como causas de evasão}

\begin{tabular}{|c|c|c|c|c|}
\hline \multirow{2}{*}{ Características do Curso } & \multirow{2}{*}{ Média } & \multirow{2}{*}{$\begin{array}{l}\text { Desvio- } \\
\text { padrão }\end{array}$} & \multicolumn{2}{|c|}{ Itens 8,9 e 10} \\
\hline & & & Soma & $\%$ \\
\hline O conteúdo do curso foi difícil para mim. & 0,98 & 2,222 & 20 & $3,09 \%$ \\
\hline $\begin{array}{l}\text { O conteúdo do curso estava aquém do que eu } \\
\text { esperava. }\end{array}$ & 1,21 & 2,656 & 31 & $4,78 \%$ \\
\hline $\begin{array}{l}\text { Achava que um curso a distância exigia } \\
\text { menos dedicação do participante. }\end{array}$ & 1,15 & 2,463 & 24 & $3,70 \%$ \\
\hline Recebi pouco ou nenhum apoio dos tutores. & 1,23 & 2,743 & 32 & $4,94 \%$ \\
\hline $\begin{array}{l}\text { Recebi pouco ou nenhum feedback } \\
\text { (comentários, instruções) sobre meus } \\
\text { exercícios. }\end{array}$ & 1,56 & 3,030 & 41 & $6,33 \%$ \\
\hline $\begin{array}{l}\text { O número de horas sugerido para estudo } \\
\text { diário foi inadequado. }\end{array}$ & 1,61 & 2,943 & 39 & $6,02 \%$ \\
\hline
\end{tabular}

Conforme Tabela 5 , verifica-se que o item com maior média foi: "Não houve compatibilidade entre minha carga de trabalho e o curso" (média $=5,28 ; \mathrm{dp}=4,50)$. Isso indica que, dentre as dificuldades profissionais, a carga de trabalho é o fator que mais explica a evasão nos cursos a distância. O desvio-padrão para o item mostrou-se alto, o que representa heterogeneidade de respostas.
É interessante observarmos o terceiro item com maior média: "Tive que viajar durante o período do curso" (média= 3,56; $\mathrm{dp}=4,45)$, que também explica a desistência do participante. Aqui novamente aparece alto o desvio-padrão.

A Tabela 6 apresenta os dados relativos a "Dificuldades Tecnológicas" com relação à soma de respostas nos pontos 8 ,

Tabela 5: Dificuldades profissionais como causas de evasão

\begin{tabular}{|c|c|c|c|c|}
\hline \multirow{2}{*}{ Dificuldades Profissionais } & \multirow{2}{*}{ Média } & \multirow{2}{*}{$\begin{array}{l}\text { Desvio- } \\
\text { padrão }\end{array}$} & \multicolumn{2}{|c|}{ Itens 8,9 e 10} \\
\hline & & & Soma & $\%$ \\
\hline $\begin{array}{l}\text { Houve aumento da minha carga de trabalho } \\
\text { em função do curso. }\end{array}$ & 3,12 & 4,06 & 116 & $17,90 \%$ \\
\hline Matriculei-me no curso contra minha vontade. & 0,36 & 1,62 & 11 & $1,70 \%$ \\
\hline $\begin{array}{l}\text { Meu chefe dificultou minha participação no } \\
\text { curso. }\end{array}$ & 0,88 & 2,41 & 25 & $3,86 \%$ \\
\hline $\begin{array}{l}\text { Meus colegas de trabalho não me davam } \\
\text { incentivo à realização do curso. }\end{array}$ & 0,82 & 2,27 & 19 & $2,93 \%$ \\
\hline $\begin{array}{l}\text { Quem faz curso a distância, no meu setor de } \\
\text { trabalho, é visto como desocupado. }\end{array}$ & 1,61 & 3,11 & 44 & $6,79 \%$ \\
\hline $\begin{array}{l}\text { Tirei férias durante o período de realização do } \\
\text { curso. }\end{array}$ & 2,28 & 4,06 & 89 & $13,73 \%$ \\
\hline Tive que viajar durante o período do curso. & 3,56 & 4,45 & 139 & 21,45 \\
\hline $\begin{array}{l}\text { Não houve compatibilidade entre a carga de } \\
\text { trabalho e o curso. }\end{array}$ & 4,89 & 4,53 & 218 & $33,64 \%$ \\
\hline $\begin{array}{l}\text { Fui transferido de setor/departamento, } \\
\text { durante o período de realização do curso. }\end{array}$ & 1,22 & 3,10 & 41 & $6,33 \%$ \\
\hline $\begin{array}{l}\text { Não houve compatibilidade entre minha carga } \\
\text { de trabalho e o curso. }\end{array}$ & 5,28 & 4,50 & 235 & $36,27 \%$ \\
\hline
\end{tabular}


Tabela 6: Dificuldades tecnológicas como causas de evasão

\begin{tabular}{|c|c|c|c|c|}
\hline \multirow{2}{*}{ Dificuldades Tecnológicas } & \multirow{2}{*}{ Média } & \multirow{2}{*}{$\begin{array}{l}\text { Desvio- } \\
\text { padrão }\end{array}$} & \multicolumn{2}{|c|}{ Itens 8,9 e 10} \\
\hline & & & Soma & $\%$ \\
\hline Não consegui acessar a Escola Virtual ENAP. & 1,94 & 3,62 & 72 & $11,11 \%$ \\
\hline $\begin{array}{l}\text { Não recebi confirmação de inscrição ou senha } \\
\text { de acesso ao curso. }\end{array}$ & 0,53 & 1,94 & 15 & $2,31 \%$ \\
\hline Não consegui acessar o curso. & 1,72 & 3,47 & 62 & $9,57 \%$ \\
\hline Tive dificuldade de acesso à internet. & 2,88 & 4,10 & 107 & $16,51 \%$ \\
\hline $\begin{array}{l}\text { Minha senha de acesso foi bloqueada mais de } \\
\text { uma vez. }\end{array}$ & 1,18 & 2,88 & 39 & $6,02 \%$ \\
\hline $\begin{array}{l}\text { O sistema não funcionou, conforme o } \\
\text { previsto, para o envio de exercícios. }\end{array}$ & 1,32 & 3,11 & 47 & $7,25 \%$ \\
\hline $\begin{array}{l}\text { O ambiente virtual do curso dificultou a minha } \\
\text { participação. }\end{array}$ & 1,07 & 2,70 & 31 & $4,78 \%$ \\
\hline Não consegui acessar os materiais do curso. & 1,62 & 3,41 & 61 & $9,41 \%$ \\
\hline
\end{tabular}

9 e 10 da escala, seu percentual em relação ao total de respondentes, média e desviopadrão.

Nessa seção, a maior dificuldade encontrada foi: "Tive dificuldade de acesso à internet" (média= 2,88; dp=4,10), seguida de: "Não consegui acessar a Escola Virtual ENAP" (média = 1,94; $\mathrm{dp}=3,62)$. O desvio-padrão indica que os participantes não foram unânimes nessa justificativa, porém as dificuldades tecnológicas encontradas parecem também influenciar menos a evasão que outros aspectos analisados na presente pesquisa.

Nos cursos com tutoria, os participantes que mais evadiram encontram-se em faixa etária compreendida entre $30 \mathrm{e}$ 39 anos, são do gênero masculino, possuem curso superior e trabalham na Região Centro-Oeste do país (Brasília) na esfera do Poder Executivo federal.

Supõe-se que esse quadro se deva ao fato de que indivíduos nessa faixa etária encontram-se, em geral, no ápice da atividade profissional, em especial, aqueles que se localizam em grandes centros urbanos, tendo como consequência um assoberba- mento de atividades profissionais, o que contribuiria para a evasão. Provavelmente são também indivíduos com responsabilidades familiares e que não encontram outro horário para realizar o curso, além do período de trabalho.

Nos cursos sem tutoria, o quadro de evadidos é semelhante, sendo a única diferença o gênero, ou seja, foram as mulheres que menos concluíram cursos dessa natureza.

Nesse caso, além dos fatores citados para os evadidos nos cursos com tutoria, supõe-se que as mulheres evadam mais dos cursos sem tutoria, tendo em vista que esse segmento da população, em geral, exerce ainda outros papéis sociais, o que faria com que a ausência do suporte de um tutor se tornasse mais um fator contributivo para a evasão.

A categoria "Dificuldades Profissionais", seguida pela categoria "Dificuldades Pessoais", foram as que mais explicaram a evasão. Já as categorias "Características do Curso" e "Dificuldades Tecnológicas" se apresentaram como as que menos influenciaram a evasão de participantes dos cursos. 


\section{Considerações finais}

À luz da revisão da literatura sobre o assunto, foram identificados e analisados os fatores que contribuem para a evasão de participantes nos cursos de educação continuada a distância em uma organização governamental responsável pela capacitação dos servidores da administração pública federal.

A ênfase dessa investigação se concentrou na descrição das características da clientela, com relação a gênero, idade, escolaridade, localização geográfica e as esferas de poder e de governo em que atuam, e na análise dos fatores que influenciaram a evasão, considerando as variáveis dificuldades pessoais, profissionais, tecnológicas e peculiaridades do curso.

No entanto, considerando que o tema é amplo, o trabalho pretendeu apresentar uma contribuição sobre o assunto voltada em especial para o segmento dos servidores públicos. Não foram, por exemplo, investigadas as questões contextuais e os resultados encontrados não foram cotejados com variáveis de suporte.

A pesquisa quantitativa realizada nos permite chegar às considerações que se seguem. No contexto observado, de um conjunto de servidores públicos, podemos constatar que o acúmulo de atividades de trabalho resultou no indicador mais forte para a desistência em completar cursos a distância.

As questões relacionadas à saúde do participante e aos seus compromissos familiares foram apontadas como o segundo fator que mais influenciou a evasão. Esses aspectos fogem ao controle do servidor, que também encontra outros dificultadores, como a falta de computador em casa.
Verificou-se que um dos motivos mais frequentes para a evasão em cursos a distância da ENAP, a saber, a ausência de tempo de dedicação por parte do participante, coincide com dados do Anuário Brasileiro Estatístico de Educação Aberta e a Distância (ABrAEAD, 2006).

Observou-se a pertinência da hipótese traçada por Zerbini (2003) no sentido de que se faz necessário investigar outras características que podem estar relacionadas à evasão, em especial, a relação entre

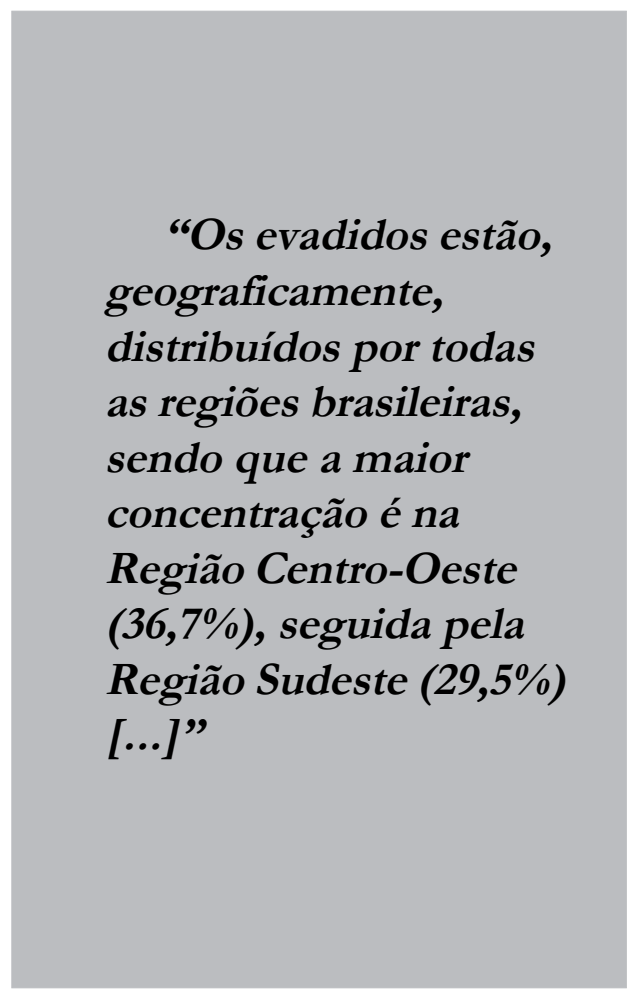

informações prévias que subsidiem a decisão do interessado em matricular-se no curso e sua avaliação sobre o esforço requerido para o cumprimento satisfatório das atividades. A clareza quanto a importância dessas variáveis trará, certamente, aprimoramentos que poderão minimizar a evasão.

Essa constatação vai ao encontro dos achados de Favero (2006), com relação à 
evasão de adultos trabalhadores em cursos oferecidos a distância, realidade dos participantes de cursos da ENAP. O autor responsabiliza o fator cansaço no final de um dia de trabalho, o que dificultaria que o servidor retomasse as atividades de capacitação em outros contextos, após a jornada profissional.

O Abraead 2006 menciona estudo exploratório indicando que outros fatores são apresentados como de maior influência na evasão, tais como, o estranhamento ao método utilizado, a avaliação de que o curso exige maior dedicação que a inicialmente esperada pelo participante e o entendimento de que o material de estudo e os recursos oferecidos foram escassos. Esses aspectos puderam também ser observados no contexto dessa pesquisa, ainda que em menor proporção, através de relatos dos coordenadores de curso da ENAP sobre mensagens recebidas dos participantes.

Para aprimoramento deste trabalho, seria importante a realização de novas pesquisas voltadas para o contexto do serviço público brasileiro, de modo a identificar peculiaridades desse segmento e compará-las com outros grupos de atores.

Seriam necessárias também novas pesquisas sobre características individuais no sentido de auxiliar o desenvolvimento de modelos teóricos de treinamento e a percepção de características que podem tornar mais eficiente o desempenho de participantes de eventos de aprendizagem. $\mathrm{E}$ ainda investigações sobre a relação de variáveis demográficas, como idade e nível de instrução, com resultados de treinamento no nível de impacto.

Os resultados poderiam também ser testados com diferentes modelos de regressão, com variáveis tanto demográficas quanto de suporte e de contexto, de modo a possibilitar sua generalização.

Seria também interessante revisitar o conceito de evasão utilizado, verificando a pertinência de ampliá-lo. Poderiam ainda ser analisados os dados demográficos dos participantes concluintes em relação aos evadidos.

(Artigo recebido em dezembro de 2008. Versão final em junho de 2009).

\section{Nota}

1 Boletim Estatístico de Pessoal. Ministério do Planejamento. n. 158. Junho, 2009.

\section{Referências bibliográficas}

Abbad, Gardênia da Silva; Carvalho, Renata Silveira; Zerbini, Thaís. Evasão em Curso a Distância via Internet: Explorando Variáveis Explicativas. RAE-eletrônica, v. 5, n. 2, Art. 17, jul./dez. 2006. 
Anuário Brasileiro Estatístico de Educação Aberta e a Distância (ABRAED). São Paulo: Instituto Monitor, 2006. (já disponivel edição de 2007 no site)

Boletim Estatístico de Pessoal. Ministério do Planejamento. n. 158. Brasilia: MP, junho, 2009. Coelno, M. L. A Evasão nos Cursos de Formação Continuada de Professores Universitários na Modalidade de Educação a Distância Via Internet - Universidade Federal de Minas Gerais, 2002.

Favero, Rute Vera Maria; Franco, Sérgio Roberto Kieling. Um estudo sobre a permanência e a evasão na Educação a Distância. Novas tecnologias na Educação. Porto Alegre, 2006. Disponível em: http://www.cinted.ufrgs.br/renote/dez2006/artigosrenote/25103.pdf. Acessado em: outubro de 2007.

GIL, Antonio Carlos. Métodos e Técnicas de Pesquisa Social. São Paulo: Atlas, 1999.

Maia, Marta de Campos; Meirelles, Fernando de Souza; Pela, Silvia Krueger. Análise dos Índices de Evasão nos Cursos Superiores a Distância do Brasil. FGV-EAESP, 2004. Disponível em: http://www.miniweb.com.br. Acessado em: abril de 2007.

Moore, Michael G.; KeArsley, Greg. Educação a Distância: uma visão integrada. São Paulo: Thomson Learning, 2007. (Tradução Roberto Galman)

Walter, Amanda Moura. Variáveis Preditoras de Evasão em Cursos a Distância. Dissertação de Mestrado, Instituto de Psicologia, Universidade de Brasília. Brasília, 2006.

Zerbini, Thaís. "Estratégias de Aprendizagem, Reações aos Procedimentos de um Curso via Internet, Reações ao Tutor e Impacto do Treinamento no Trabalho”. Dissertação de Mestrado, Instituto de Psicologia, Universidade de Brasília. Brasília, 2003. 


\section{Resumo - Resumen - Abstract}

\section{Evasão em cursos de educação continuada a distância: um estudo na Escola Nacional de Administração Pública \\ Tarcilena Polisseni Cotta Nascimento e Aniely Kaukab Esper}

A análise da literatura brasileira sobre educação a distância é ainda limitada no que diz respeito a estudos que investiguem o fenômeno da evasão, em especial, em contextos de escolas de governo. Este artigo procura identificar e analisar os fatores que contribuem para a evasão de participantes nos cursos de educação continuada a distância em uma organização governamental responsável pela capacitação dos servidores da administração pública federal. A ênfase das investigações encontra-se nas variáveis referentes às dificuldades pessoais, profissionais e tecnológicas, às peculiaridades do curso e características da clientela, contrastadas com as variáveis demográficas referentes à evasão em cursos a distância mediados por tecnologias da informação e da comunicação. O trabalho é embasado em metodologia quantitativa, por meio de pesquisa descritiva de campo junto aos participantes, valendo-se do uso de questionário eletrônico. Procura contribuir para investigações sobre o tema, em especial no que se refere aos servidores públicos.

Palavras-chave: educação a distância, evasão, qualificação de servidores públicos.

\section{Evasión en cursos de educación continuada a distancia: un estudio en la Escuela Nacional de Administración Pública}

Tarcilena Polisseni Cotta Nascimento y Aniely Kaukab Esper

El análisis de la literatura sobre educación a distancia todavía es limitado en lo que se refiere a estudios que investiguen el fenómeno de la evasión, en especial, en contextos de escuelas de gobierno. El presente artículo procura identificar y analizar los factores que contribuyen a la evasión de alumnos en los cursos de educación continuada a distancia en una organización gubernamental, responsable de la capacitación de los funcionarios de la administración pública federal. El énfasis de las investigaciones se concentra en las variables referentes a las dificultades personales, profesionales y tecnológicas, en las peculiaridades del curso y en las características de la clientela, contrastadas con las variables demográficas referentes a la evasión en cursos a distancia mediados por tecnologías de la información y de la comunicación. El trabajo está basado en metodología cuantitativa, mediante investigación descriptiva de campo realizada junto a los participantes, utilizando cuestionario electrónico. Concientes de que el tema es vasto, no se pretende, aquí, agotarlo. Busca contribuir para el amplio campo del tema sobre la evasión en EAD, en especial sobre los funcionarios públicos.

Palabras clave: educación a distancia, evasión, capacitación de los funcionarios públicos.

\section{Drop-out from continued education distance courses: a case study on National School of Public Administration}

Tarcilena Polisseni Cotta Nascimento and Aniely Kaukab Esper

Analyses available in the literature on distance learning are still limited with regard to studies that investigate the drop-out phenomenon, particularly in public service schools. This article seeks to identify and analyze factors which contribute to lead students to drop out from continuededucation distance learning courses in a governmental organization responsible for training civil servants of the federal public administration. The investigations are focused on variables related to personal, professional and technological difficulties, to the unique features of this type of course, and to the characteristics of its clients contrasted with demographic variables related to drop-out 
from distance learning courses mediated by information and communication technologies. The article is based on a quantitative methodology applied to the participants through a descriptive field survey using an electronic questionnaire. It deals with drop-out from distance learning courses, methodological aspects of the survey, outcomes and final considerations. Aware that this is a comprehensive topic, it is not the intention of the article to exhaust it.

Keywords: distance learning, drop out rates, civil servants training.

Tarcilena Polisseni Cotta Nascimento

Especialista em Educação a Distância pela Universidade de Brasília e mestranda em Educação pela Universidade Católica de Brasília. Desde 2004, responde pela Coordenação-Geral de Educação a Distância, vinculada à Diretoria de Desenvolvimento Gerencial da ENAP.

Contato: tarcilena.nascimento@enap.gov.br

\section{Aniely Esper}

Especialista em Educação a Distância, pela Universidade de Brasília. Há cinco anos, atua como coordenadora de Cursos a Distância na ENAP. É responsável pela migração dos cursos a distância para o ambiente Moodle, pela criação e manutenção de comunidades virtuais e pela oferta de cursos.

Contato: kaukabesper@gmail.com 


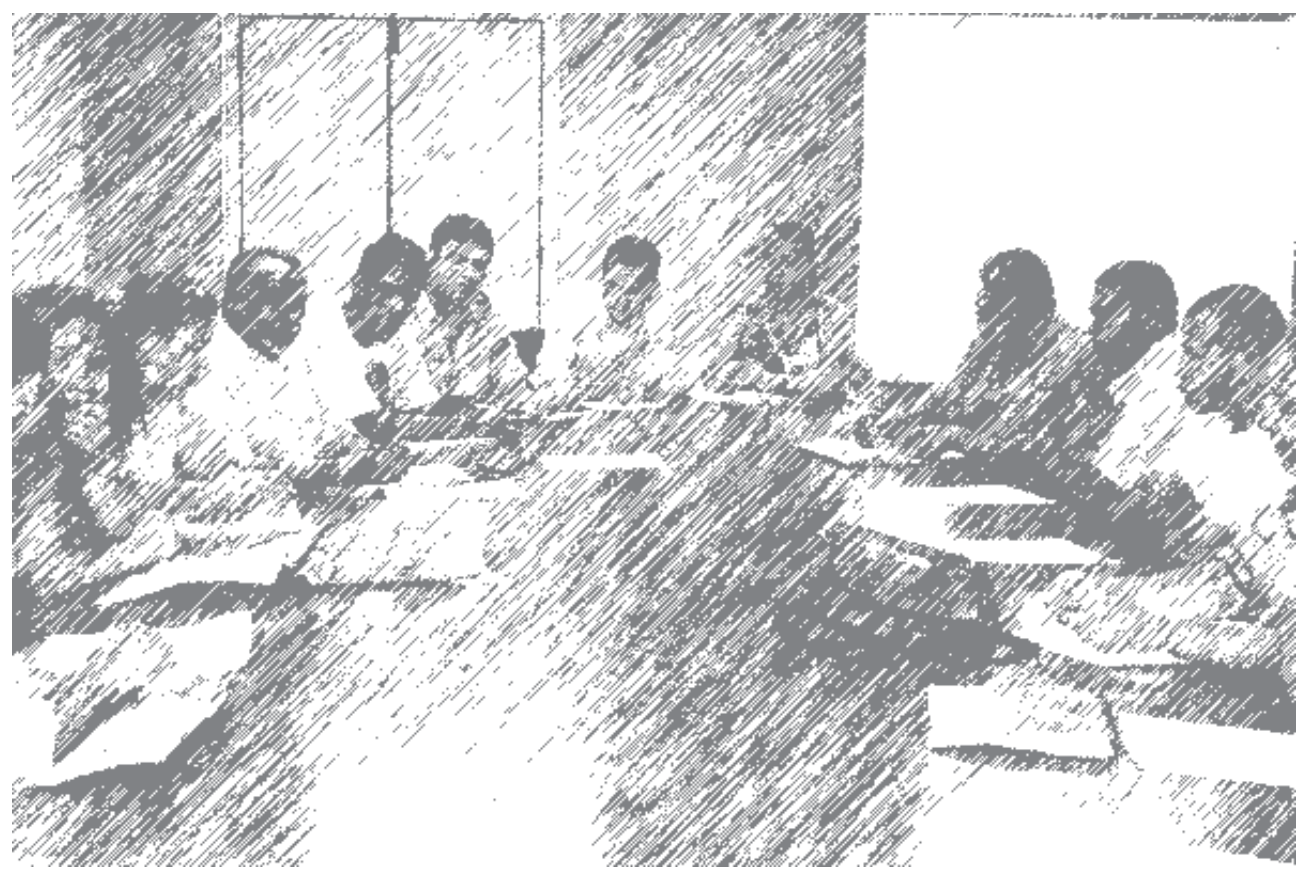

